\title{
Network Marketing Performance Evaluation System Construction
}

\author{
Qing YUE ${ }^{1, a}$, Liang-Hui ZHAO ${ }^{2, b}$ \\ WUYI university \\ ${ }^{1}$ Jiangmen, Guangdong, China \\ 2Jiangmen, Guangdong,China \\ a870624251@qq.com, b42313611@qq.com
}

Keywords: Internet marketing, Performance evaluation, Fuzzy evaluation.

\begin{abstract}
The main goal of establishing network marketing performance evaluation system is to evaluate whether the network marketing activities carried out by enterprises have achieved the expected results. In this paper, we design some indexes from the aspects of cost, output and competitiveness. Combining the fuzzy comprehensive evaluation theory and the analytic hierarchy process, this paper establishes the fuzzy evaluation model to judge the network marketing performance initially.
\end{abstract}

\section{Introduction}

With the development of the Internet and communication technologies, the size of Internet users in our country has grown, and the number of websites has grown rapidly. Internet marketing has gradually become a commercial application model. At present, the network marketing market is in a state of strong growth. it needs to combine the internet with marketing if a company wants further development, which means to change its traditional marketing environment and marketing philosophy based on the characteristics of the enterprise, Internet marketing strategy. However, there are still some misunderstandings and lack of systematic understanding in the current understanding of network marketing mode. In addition, the influence of different network marketing modes on the operation and management of enterprises is different, so we need to establish an objective evaluation network marketing model on the enterprise's development status, operational capacity and operating costs and other content of the enterprise network marketing performance evaluation system, in order to find the problems existing in enterprise network marketing, so as to improve the existing network marketing model, establish a network for the enterprise marketing mode. The emergence of network marketing, changing the traditional management models and codes of conduct, to build an effective network marketing performance evaluation index system, to provide enterprises with a theoretical tool that can evaluate, guide, decision-making.

\section{Related Research}

\section{Domestic Research}

Compared with other countries, domestic network marketing related research started relatively late for the network marketing theory and strategy are lack of a sound theoretical system. Liu Man-feng (2001) defined Internet marketing as a process of implementing product pricing, promotion and distribution by implementing the enterprise's ideas and goals with new ways and concepts through Internet, communication technology and digital exchange telecommunications The new marketing activities, he used analytic hierarchy process to determine the weight of the evaluation system at all levels, pointed out that the establishment of the main principles of network marketing performance evaluation system is purposeful, comprehensive and practical. CCID Consulting Co., Ltd. in the "2005-2006 Annual Report on China's Internet Marketing Market and Investment Opportunities" will be divided into online marketing Internet marketing, Email Marketing, search engine marketing, wireless network marketing, online community marketing and business platform marketing Six main modes. 
Zhu Guangxi (2008) established an index system for the sustainable development of listed companies from the perspective of data envelopment analysis (DEA), and evaluated the capability of enterprises for sustainable development by using the SGDEA model [1]. Wen Yanping (2009) established a set of index system of network marketing performance from the three aspects of marketing target, marketing index and marketing data, and calculated the network marketing performance using the comprehensive index method [2]. According to Gao Wen-hai (2006), from four aspects of website effectiveness, network marketing efficiency and network marketing efficiency, four levels of evaluation index system of 11 second-level indicators and 44 third-level indicators are constructed. Combining with the multi-level fuzzy comprehensive evaluation method, Based on AHP and Delphi method to evaluate the comprehensive performance of network marketing [3].Wang Yan (2006) pointed out that the network marketing model is a model of enterprises' Internet marketing, which connects enterprises and customers by some means and achieves the goal of enterprise marketing. From the macro-environment and micro-environment of network marketing fee, Behavioral and psychological analysis, that the marketing model to stimulate consumption patterns, interactive communication model, database marketing model and community-based Internet marketing model four types of models [4].

\section{Foreign Related Research}

Foreign network marketing research started earlier and developed more and accumulated more theory and experience abroad. The study of network marketing mainly focuses on the basic concepts of network marketing, network brand, network marketing model and customer relationship management. The Chartered Institute of Marketing (CIM) defines marketing as a management process that identifies, predicts, and serves the needs of customers. The American Marketing Association considers marketing to be an activity, a set of institutions, and the process of creating, communicating, delivering, and exchanging products that provide value to customers, customers, partners, and society.

Gladson (2009) validates the connection between EQ tools and early marketing effectiveness and explores the impact of EQ on the efficiency of corporate marketing when studying the relationship between Nigerian business organizations and market effectiveness [5]. Wills and Kennedy (1990) argue that marketing activities are the result of a match between the organization's human, material, and financial resources, and its customers' needs. Such matching is generally controlled by the formal department headed by the top executives of the organization. Coordinate and control the price of the product or service, the style of the promotion, and the place where it is provided [6]. Kotler (1984) defines marketing as a process of meeting needs through exchange, "social and management processes in which individuals and groups get what they need by creating and exchanging products and values," and he believes that clients will only do business, If they feel their needs are met, it is clear that the value of the transaction cannot exceed the amount the customer is prepared to pay to meet their needs. P. Tailor pointed out that marketing is not to provide products or services, which is essentially to change the needs and needs of customers.

In the existing researches, the researches on network marketing performance evaluation system are still scarce, and the research perspectives of different scholars are also different. There is a lack of a unified index selection standard and less empirical research. The evaluation index is basically based on the enterprise perspective Established, and truly meet the specific environment of enterprise network marketing and operational evaluation system is still relatively scarce, therefore, it is necessary at home and abroad on the basis of research, combined with the actual situation, to build an enterprise network marketing performance evaluation system.

\section{Establishment of Fuzzy Comprehensive Evaluation System}

In practice, the evaluation of a thing usually involves many or more indicators, which requires that we can not only evaluate a thing from a certain factor, but comprehensively evaluate the thing according to a number of factors, Comprehensive evaluation is a comprehensive evaluation of things that are affected by multiple influencing factors. Generally speaking, we use the multi-level 
evaluation model more in the fuzzy comprehensive evaluation of economic benefits, and we need to grasp the corresponding index information in the process of formulating the evaluation plan, and determine the evaluation set of the fuzzy evaluation index set and the indicator level.

Fuzzy comprehensive evaluation is a comprehensive evaluation method based on mathematical model. It is based on the theory of membership degree of fuzzy mathematics, and uses fuzzy mathematics to make an overall judgment on the things that are influenced by many factors. Generally, we use the fuzzy comprehensive evaluation to analyze and evaluate the factors that affect the comprehensive economic benefits. The main factors affecting the comprehensive economic benefits are the capital flow, the return on assets, and the bad accounts receivable turnover rate. The results of these factors generally are ambiguous There is no specific limit, the use of fuzzy comprehensive evaluation to determine the impact of sub-factors on the results of the use of funds to determine the various factors in the overall economic benefits of the important position. The main steps of fuzzy comprehensive evaluation are:

\section{Determining Factor Sets and Judging Sets}

The set of judgment factors is a set of each influencing factor. Supposing there are $\mathrm{n}$ evaluation factors, they are $\mathrm{u}_{1}, \mathrm{u}_{2}, \mathrm{u}_{3}, \ldots, \mathrm{u}_{n}$, Then the set of $\mathrm{n}$ evaluation factors is the set of factors $U$, that is $U=\left\{\mathrm{u}_{1}, \mathrm{u}_{2}, \mathrm{u}_{3}, \ldots, \mathrm{u}_{n}\right\}$.

The judgment set is the set of all the evaluation results of the judgment object to the judgment object. According to the different situations, the judgment result can be divided into $\mathrm{m}$ levels, namely $\mathrm{v}_{1}, \mathrm{v}_{2}, \mathrm{v}_{3}, \cdots, \mathrm{v}_{m}$, then this level set is the judgment set $V=\left\{\mathrm{v}_{1}, \mathrm{v}_{2}, \mathrm{v}_{3}, \ldots, v_{\mathrm{m}}\right\}$.

\section{Determine the Weight of Indicators}

Weight value indicates the importance of each of the evaluation indicators, this paper is mainly the use of analytic hierarchy process (AHP) to determine the weight of each of the evaluation indicators, the composition of the set is the weight set:

$$
W=\left\{\mathrm{w}_{1}, \mathrm{w}_{2}, \mathrm{w}_{3}, \cdots, w_{n}\right\} \sum_{i=1}^{n} w_{i}=1 \mathrm{w}_{\mathrm{i}} \geq 0 .
$$

\section{Univariate Fuzzy Evaluation}

One-factor fuzzy evaluation is to judge a single factor, in order to determine the degree of each evaluation index membership. Assuming that the $i$ factor $u_{i}(i=1,2, \cdots, n)$ of the factor set is judged, it is expressed as the degree of $\mathrm{v}_{\mathrm{j}}(\mathrm{j}=1,2, \cdots, n)$ membership of the $\mathrm{j}$ element of the judgment set ${ }^{r_{i j}}$, which is the corresponding degree of membership ${ }^{a_{i}}$, the fuzzy set can be used to represent the judgment result of the $i$ factor $u_{i}$ :

$$
R_{i}=\left\{r_{i 1}, r_{i 2}, r_{i 3}, \ldots, r_{i m}\right\} .
$$

Among them, $R_{i}$ is a single factor judgment set, there is a single factor judgment set for each corresponding factor:

$$
\begin{gathered}
R_{1}=\left\{r_{11}, r_{12}, r_{13}, \ldots, r_{1 \mathrm{~m}}\right\} \\
R_{2}=\left\{r_{21}, r_{22}, r_{23}, \ldots, r_{2 m}\right\} \\
\vdots \\
R_{\mathrm{n}}=\left\{r_{n 1}, r_{n 2}, r_{n 3}, \ldots, r_{n m}\right\}
\end{gathered}
$$


The above $\mathrm{n}$ single factor evaluation set can form a total evaluation matrix:

$$
R=\left[\begin{array}{c}
R_{1} \\
R_{2} \\
\vdots \\
R_{n}
\end{array}\right]=\left[\begin{array}{cccc}
r_{11} & r_{12} & \cdots & r_{1 m} \\
r_{21} & r_{22} & \cdots & r_{2 m} \\
\vdots & \vdots & \vdots & \vdots \\
r_{n 1} & r_{n 2} & \cdots & r_{n m}
\end{array}\right]
$$

$\mathrm{R}$ is a single factor matrix.

\section{Establish Fuzzy Comprehensive Evaluation Model}

The purpose of the single-factor fuzzy evaluation is to derive the comprehensive evaluation results of all the factors on the object of judgment. Taking into account the different weights of each evaluation index, we need to combine the weight set of the evaluation index and the evaluation matrix, and then conduct a comprehensive evaluation. The established comprehensive evaluation model is:

$$
E=W * R=\left(\begin{array}{llll}
W_{1} & W_{2} & \cdots & W_{n}
\end{array}\right) *\left[\begin{array}{cccc}
r_{11} & r_{12} & \cdots & r_{1 m} \\
r_{21} & r_{22} & \cdots & r_{2 m} \\
\vdots & \vdots & \vdots & \vdots \\
r_{n 1} & r_{n 2} & \cdots & r_{n m}
\end{array}\right]=\left(\begin{array}{llll}
e_{1} & e_{2} & \cdots & e_{m}
\end{array}\right)
$$

In the above formula, $E$ is the result of fuzzy comprehensive evaluation, $e_{j}(j=1,2, \cdots, m)$ is the fuzzy comprehensive evaluation index.

\section{Build a Network Marketing Performance System Based on Fuzzy Theory}

Kotler (1977) argues that operational marketing efficiency has a client philosophy, integrated marketing organization, sufficient market information, strategic positioning and operational efficiency. The effectiveness of marketing depends on the depth of the five components and They are integrated with each other. Nwokah (2006) pointed out that the four basic dimensions of judging marketing effectiveness are enterprise, customer, competitiveness and exogenous factors. Marketing strategy, marketing creativity, marketing execution, infrastructure and exogenous factors will affect the market Marketer's marketing level.

\section{Network Marketing Performance Evaluation Index}

According to the scientific, systematic and operable principles of establishing network evaluation index system, this paper initially designs a more scientific and complete index system of network marketing performance evaluation, which includes three levels, three categories, ten Two indicators. It is shown in Table 1.

Table 1 evaluation index

\begin{tabular}{|l|l|l|}
\hline Target level & \multicolumn{1}{|c|}{ A level of indicators } & Secondary indicators \\
\hline \multirow{4}{*}{$\begin{array}{l}\text { Maximize } \\
\text { network } \\
\text { marketing } \\
\text { effectiveness }\end{array}$} & Cost indicators & $\begin{array}{l}\text { Website construction fee } \\
\text { Website maintenance fee } \\
\text { Marketing staff costs } \\
\text { Advertising costs }\end{array}$ \\
\cline { 2 - 3 } & Output indicators & $\begin{array}{l}\text { Page hits } \\
\text { View conversion rates } \\
\text { Assets and liabilities } \\
\text { Sales revenue growth rate }\end{array}$ \\
\cline { 2 - 3 } & \multirow{2}{*}{ Competitiveness index } & $\begin{array}{l}\text { Market share } \\
\text { Brand awareness } \\
\text { Customer Loyalty } \\
\text { Customer satisfaction }\end{array}$ \\
\hline
\end{tabular}


On the determination of the value of various indicators, I suggest using Delphi method, through expert advice to determine the weight of each indicator.

\section{Network Marketing Performance Fuzzy Evaluation System}

We divide the evaluation factors of network marketing performance into two layers according to their characteristics. We must first make a comprehensive evaluation of each layer and then conduct a higher-level comprehensive evaluation of the evaluation results.

The factors that affect the network marketing performance evaluation are:

$$
\left.U=\left\{U_{1} \text { (Cost indicators), } U_{2} \text { (Output indicators), } U_{3} \text { (Competitiveness index }\right)\right\}
$$

The evaluation set of network marketing performance is:

$$
\left.V=\left\{V_{1} \text { (Higher }\right), V_{2}(\text { High }), V_{3}(\text { General }), V_{4}(\text { low }), V_{5}(\text { lower })\right\}
$$

Factor $\mathrm{U}_{\mathrm{i}}(\mathrm{i}=1,2,3)$ is determined by the following factors:

$U_{1}=\{$ Website construction fee, Website maintenance fee, Marketing staff costs, Advertising costs $\}$

$U_{2}=\{$ Page hits, View conversion rates, Assets and liabilities, Sales revenue growth rate $\}$

$U_{3}=\{$ Market share, Brand awareness, Customer Loyalty,Customer satisfaction $\}$

Mark $U_{i}=\left\{\mathrm{u}_{i 1}, \mathrm{u}_{i 2}, \mathrm{u}_{i 3}, \ldots, u_{i k}\right\}(\mathrm{i}=1,2,3)$

First, make a comprehensive judgment on each of the $k$ factors of $U_{\mathrm{i}}$. There:

$$
E_{i}=W_{i} * R_{i} \quad(i=1,2,3)
$$

Then, do a comprehensive assessment of the total: $E=W * R$

Where, $W$ is a weight vector, $R$ is the total evaluation matrix, there: $R=\left[\begin{array}{c}E_{1} \\ E_{2} \\ E_{3}\end{array}\right]$

The final $E$ is a comprehensive evaluation of all the factors.

\section{Summary}

The establishment of a scientific and effective network marketing performance evaluation system has its unique significance. In the theoretical sense, starting from the definition of network marketing theory and mode, it has studied the existing achievements both at home and abroad, applied the theory of fuzzy mathematics to economic management Field, based on the fuzzy evaluation model to build a more complete network marketing model of evaluation system, in order to assess the existing marketing model of enterprises, has an important practical significance for the study of network marketing performance.

From a practical point of view, for enterprises, the establishment of network marketing performance evaluation system will help enterprises better find the problems in the network marketing activities, evaluate their own network marketing activities, help enterprises choose an efficient decision. The fuzzy evaluation of the network marketing model also helps companies reduce waste of resources to help enterprises achieve the goal of full marketing. For consumers, companies choose more efficient model, consumers will be more direct understanding of corporate information, better access to the information they need to break the time and space constraints to meet the needs of consumers themselves. 


\section{References}

[1].Zhu Guangxi, Ma Zhanxin. A Study of Enterprise Sustainable Development Based on DEA [J].Journal of Management Science, 2008,16 (S1): 358-361.

[2].Wen Yanping, Shi Jiahua. Network marketing performance evaluation index system [J]. Intelligence Magazine, 2009,28 (11): 92-96.

[3].Wenhai Gao, Yu SU , Lijie Cao .A Comprehensive Evaluation Model of Internet Marketing Performance Based on Multi-level Fuzzy Method [J]., Market Review, 2006, (27): 102-103

[4].Yan Wang. China's enterprise network marketing model and performance evaluation [D]. Harbin Engineering University, 2006

[5].N. Gladson Nwokah, Augustine I. Ahiauzu, (2009) "Emotional intelligence and marketing effectiveness", Marketing Intelligence \& Planning, Vol. 27 Issue: 7, pp.864-881

[6].Gordon Wills, Sherril H. Kennedy, John Cheese, Angela Rushton, (1990) "Maximising Marketing Effectiveness", Management Decision, Vol. 28 Issue: 2 